\title{
Genomic comparisons of Brucella spp. and closely related bacteria using base compositional and proteome based methods
}

\author{
Jon Bohlin ${ }^{1 *}$, Lars Snipen², Axel Cloeckaert ${ }^{3}$, Karin Lagesen ${ }^{4}$, David Ussery ${ }^{5}$, Anja B Kristoffersen ${ }^{4,6}$, \\ Jacques Godfroid ${ }^{7}$
}

\begin{abstract}
Background: Classification of bacteria within the genus Brucella has been difficult due in part to considerable genomic homogeneity between the different species and biovars, in spite of clear differences in phenotypes. Therefore, many different methods have been used to assess Brucella taxonomy. In the current work, we examine 32 sequenced genomes from genus Brucella representing the six classical species, as well as more recently described species, using bioinformatical methods. Comparisons were made at the level of genomic DNA using oligonucleotide based methods (Markov chain based genomic signatures, genomic codon and amino acid frequencies based comparisons) and proteomes (all-against-all BLAST protein comparisons and pan-genomic analyses).

Results: We found that the oligonucleotide based methods gave different results compared to that of the proteome based methods. Differences were also found between the oligonucleotide based methods used. Whilst the Markov chain based genomic signatures grouped the different species in genus Brucella according to host preference, the codon and amino acid frequencies based methods reflected small differences between the Brucella species. Only minor differences could be detected between all genera included in this study using the codon and amino acid frequencies based methods.

Proteome comparisons were found to be in strong accordance with current Brucella taxonomy indicating a remarkable association between gene gain or loss on one hand and mutations in marker genes on the other. The proteome based methods found greater similarity between Brucella species and Ochrobactrum species than between species within genus Agrobacterium compared to each other. In other words, proteome comparisons of species within genus Agrobacterium were found to be more diverse than proteome comparisons between species in genus Brucella and genus Ochrobactrum. Pan-genomic analyses indicated that uptake of DNA from outside genus Brucella appears to be limited.

Conclusions: While both the proteome based methods and the Markov chain based genomic signatures were able to reflect environmental diversity between the different species and strains of genus Brucella, the genomic codon and amino acid frequencies based comparisons were not found adequate for such comparisons. The proteome comparison based phylogenies of the species in genus Brucella showed a surprising consistency with current Brucella taxonomy.
\end{abstract}

\footnotetext{
* Correspondence: jon.bohlin@nvh.no

'Norwegian School of Veterinary Science, Department of Food Safety and Infection Biology, Epicenter, Ullevålsveien 72, PO Box 8146 Dep, NO-0033

Oslo, Norway

Full list of author information is available at the end of the article
}

\section{Ciomed Central}

C 2010 Bohlin et al; licensee BioMed Central Ltd. This is an Open Access article distributed under the terms of the Creative Commons Attribution License (http://creativecommons.org/licenses/by/2.0), which permits unrestricted use, distribution, and reproduction in any medium, provided the original work is properly cited. 


\section{Background}

The genus Brucella belongs to the $\alpha$-Proteobacteria order and consists of mostly intra-cellular bacteria that are known to be pathogenic in a wide range of mammal hosts [1]. The ailments caused by the different species and strains from genus Brucella are known collectively as brucellosis [1]. Brucellosis is a contagious zoonotic disease known to affect many different mammals ranging from livestock and humans to a wide variety of marine mammals. Each species or strain, however, has a narrow host range [1].

The Brucella genus has traditionally been classified into six species: $B$. melitensis, $B$. suis, $B$. abortus, B. neotomae, B. ovis, and B. canis, which are reflective of host preference. In 1985, it was proposed that the six Brucella species should be grouped as biovars of a single species based on DNA-DNA hybridization studies [2]. The Brucella Taxonomic Subcommittee of the International Committee on Systematics of Prokaryotes adopted this proposition. However, the international community of Brucella researchers has never accepted this change and a return to the pre-1986 taxonomy was advocated and eventually adopted by the Brucella Taxonomic Subcommittee [3]. Genus Brucella has been further expanded with a set of recently discovered species. Such species include $B$. ceti and $B$. pinnipedialis that have been isolated from cetaceans and pinnipeds [4]. $B$. microti has been isolated from the common vole [5], and $B$. inopinata was isolated from a breast implant infection in an woman with clinical signs of brucellosis [6].

The genomes sequenced from genus Brucella are also known to be very similar in terms of both base composition and genome size [1]. All sequenced species have a GC content of approximately $57 \%$, and most genomes consist of approximately $3.3 \mathrm{Mbp}$ divided on two chromosomes (see Table 1). None of the sequenced members of the Brucella genus have any plasmids reported [http://www.ncbi.nlm.nih.gov/genomes/lproks.cgi].

The first Brucella species to be sequenced was $B$. melitensis 16M (biovar 1) [7] followed closely by B. suis 1330 (biovar 1) [8]. As more genomes are being sequenced, taxonomic classification of the Brucella genus is becoming more difficult, and many different methods have been applied [9]. The challenges involved in taxonomical classification of Brucella spp. are largely linked to the fact that marker genes typically used for phylogenetic classification are either missing or too similar to give any meaningful results $[9,10]$. Additionally, marker gene based methods like MLST and $16 \mathrm{~S}$ rRNA do not directly reflect changes in gene content and may therefore fail to reproduce a broader view of the differences between species, strains, and biovars
$[10,11]$. SNP analysis gives a better overview of changes happening at the genome level, but does not directly reflect changes in gene content [10]. Hence, taxonomic classification of Brucella spp. is a challenging task touching on difficult taxonomic and phylogenetic issues in prokaryotic species definition as a whole [9].

The aim of this study was to examine the strength and weaknesses of a set of methods for phylogenetic classification based on whole genome comparisons. This was carried out using a number of sequenced genomes from species and strains taken from genus Brucella and the closely related genus Agrobacterium and genus Ochrobactrum. This study was motivated by the genomic homogeneity and the difficult phylogenetic assessment of genus Brucella. Genomic comparisons were performed using a number of different methods that reflect changes at both the proteome level and the base composition level.

The comparison methods reflecting DNA composition used in this study include oligonucleotide based $0^{\text {th }}, 1^{\text {st }}$, and $2^{\text {nd }}$ order Markov chain genomic signature models (ZOM, FOM, SOM, respectively) [12], and codon and amino acid frequencies analyses [13].

For the proteome based comparisons of the genomes, the Prodigal gene finder [14] was used to predict open reading frames (ORFs) in all genomes used in the study (See Table 1). Whole genome BLAST comparisons were subsequently performed between all proteomes, i.e. allagainst-all gene comparisons between all genomes according to the guidelines given by Ussery et al. [15]. In addition, pan- and core genome analyses $[16,17]$ were carried out to map gene exchange in sequenced members of genus Brucella and the closely related phylogenetic genera such as Agrobacterium and Ochrobactrum [18].

Scholz and co-workers [18] have carried out a thorough 16S rRNA analysis and we refer to that article for these results.

Of the methods described above, the Markov chain models and codon and amino acid frequencies based analyses best reflect base compositional differences and whole genome mutational bias $[12,19]$. The oligonucleotide based methods are sensitive to mutations at the genome level, and therefore share certain similarities with the whole genome SNP analyses conducted by Foster et al. [10]. The BLAST comparisons and pan-genomic analyses focus on gene content comparisons and gene exchange and may thus be considered as complementary to the oligonucleotide frequencies based methods that mirror base compositional differences. To the best of our knowledge, recent whole genome based gene comparisons of Brucella species, similar to the work conducted here, have only been carried out for 5 
Table $10^{\text {th }}$ order Markov chain model based cluster groups of Brucella genomes

\begin{tabular}{|c|c|c|c|c|c|c|}
\hline Name & Accession & Database & Group & $\% G C$ & Size (mbp) & Host \\
\hline Brucella abortus 2308 (biovar 1) & AM040264.1 & Genbank/NCBI & 1 & 57 & 3.28 & Cattle \\
\hline Brucella abortus $2308 \mathrm{~A}^{\S}$ & VBI00022-VBI00023 & PATRIC & 1 & 57 & 3.31 & Cattle \\
\hline Brucella abortus 9-941 (biovar 1) & AE017223.1 & Genbank/NCBI & 1 & 57 & 3.28 & Cattle \\
\hline Brucella abortus S19 (biovar 1) & CP000887.1 & Genbank/NCBI & 1 & 57 & 3.29 & Cattle \\
\hline Brucella canis ATCC 23365 & CP000872.1 & Genbank/NCBI & 1 & 57 & 3.32 & Dog \\
\hline Brucella inopinata $\mathrm{BO}^{\S}$ & VBI00041-VBI00043 & PATRIC & 1 & 57 & 3.37 & Human \\
\hline Brucella melitensis 16M (biovar 1) & AE008917.1 & Genbank/NCBI & 1 & 57 & 3.32 & Sheep, goat \\
\hline Brucella melitensis $63 / 9$ (biovar 2) & ACEM01000000 & Broad Institute & 1 & 57 & 3.29 & Sheep, goat \\
\hline Brucella melitensis ATCC 23457 (biovar 2) & СР001488.1 & Genbank/NCBI & 1 & 57 & 3.28 & Sheep, goat \\
\hline Brucella ovis ATCC 25840 & СР000709.1 & Genbank/NCBI & 1 & 57 & 3.28 & Sheep \\
\hline Brucella sp. $\mathrm{BO}^{\S}$ & VBI00103-VBI00105 & PATRIC & 1 & 57 & 3.28 & Human \\
\hline Brucella suis 1330 (biovar 1) & AE014291.4 & Genbank/NCBI & 1 & 57 & 3.31 & Pig \\
\hline Brucella suis ATCC 23445 (biovar 2) & СР000911.1 & Genbank/NCBI & 1 & 57 & 3.31 & Pig, hare \\
\hline Brucella ceti B1/94 & ACEK01000000 & Broad Institute & 2 & 58 & 3.34 & Dolphin, porpoise \\
\hline Brucella ceti M13/05/1 & ACBP01000000 & Broad Institute & 2 & 58 & 3.34 & Dolphin, porpoise \\
\hline Brucella ceti M490/95/1§ & ACEJ01000000 & Broad Institute & 2 & 58 & 3.35 & Dolphin, porpoise \\
\hline Brucella ceti M644/93/1 $1^{\S}$ & ACBO01000000 & Broad Institute & 2 & 58 & 3.33 & Dolphin, porpoise \\
\hline Brucella pinnipedialis B2/94 ${ }^{\S}$ & ACBN01000000 & Broad Institute & 2 & 58 & 3.34 & Seal \\
\hline Brucella pinnipedialis M292/94/1 ${ }^{\S}$ & ACEF01000000 & Broad Institute & 2 & 58 & 3.37 & Seal \\
\hline Brucella sp. F5 $/ 99^{\S}$ & ACFF01000000 & Broad Institute & 2 & 58 & 3.4 & Dolphin \\
\hline Brucella abortus 86/8/59 (biovar 2) & ACBJ01000000 & Broad Institute & 3 & 58 & 3.32 & Cattle \\
\hline Brucella melitensis Ether (biovar 3$)^{\S}$ & ACEI01000000 & Broad Institute & 3 & 57 & 3.28 & Sheep, goat \\
\hline Brucella melitensis Rev.1 (biovar 1$)^{\S}$ & ACEG01000000 & Broad Institute & 3 & 57 & 3.31 & Sheep, goat \\
\hline Brucella neotomae $5 \mathrm{~K} 33^{\S}$ & ACEH01000000 & Broad Institute & 3 & 58 & 3.33 & Rodent \\
\hline Brucella sp. $83 / 13^{\S}$ & ACBQ01000000 & Broad Institute & 3 & 58 & 3.29 & Rodent \\
\hline Brucella suis 513 (biovar 5) $^{\S}$ & ACBK01000000 & Broad Institute & 3 & 58 & 3.15 & Pig \\
\hline Brucella suis 686 (biovar 3$)^{\S}$ & ACBL01000000 & Broad Institute & 3 & 58 & 3.3 & Pig \\
\hline Brucella pinnipedialis M163/99/10 & ACBM01000000 & Broad Institute & 4 & 59 & 3.41 & Seal \\
\hline Brucella abortus 292 (biovar 4) $^{\S}$ & ACBH01000000 & Broad Institute & 5 & 58 & 3.28 & Cattle \\
\hline Brucella abortus 870 (biovar 6) $^{\S}$ & ACBG01000000 & Broad Institute & 5 & 58 & 3.27 & Cattle \\
\hline Brucella abortus C68 (biovar 9) $)^{\S}$ & ACEL01000000 & Broad Institute & 5 & 58 & 3.27 & Cattle \\
\hline Brucella abortus Tulya (biovar 3$)^{\S}$ & ACBI01000000 & Broad Institute & 5 & 58 & 3.31 & Human \\
\hline Agrobacterium radiobacter $\mathrm{K} 84$ & СР000628.1 & Genbank/NCBI & 6 & 60 & 6.66 & Plant \\
\hline Agrobacterium tumefaciens C58 & AE007869.2 & Genbank/NCBI & 6 & 59 & 4.92 & Plant \\
\hline Agrobacterium vitis $\mathrm{S} 4$ & CP000633.1 & Genbank/NCBI & 6 & 58 & 5.01 & Plant \\
\hline Ochrobactrum anthropi ATCC 49188 & СР000758.1 & Genbank/NCBI & 6 & 56 & 4.78 & Human, plant \\
\hline Ochrobactrum intermedium LMG $3301^{\S}$ & VBI00028-VBI00031 & PATRIC & 6 & 58 & 4.73 & Human \\
\hline
\end{tabular}

${ }^{\S}$ Genomes not assembled; therefore GC content and genome size are only approximate values

Brucella genomes (B. ovis ATCC25840, B. suis 1330 (biovar 1), B. abortus 9-941 (biovar 1), B. melitensis $16 \mathrm{M}$ (biovar 1) and B. abortus 2308 (biovar 1)) by Tsolis et al. [20]. In the present work however, we perform whole genome comparisons of 32 Brucella genomes (Table 1 ) using a variety of different genomic methods to obtain deeper insight into the obscure evolution of genus Brucella. In addition to the 32 Brucella genomes, we also include three sequenced genomes from genus Agrobacterium, A. radiobacter K84, A. tumefaciens C58, A. vitis S4, and two from genus Ochrobactrum, $O$. anthropi ATCC 49188 and O. intermedium LMG 3301, to examine the relative difference between these closely related microbes [18].

\section{Results}

\section{Markov chain analyses}

The outcomes of the Markov chain model based genomic signatures analyses are shown in figures 1 and 2 . Figure 1 shows a set of cluster groups obtained using the ZOM based heatmap. Table 1 describes these cluster groups in more detail. The ZOM, FOM and SOM based genomic signatures, which were used to produce the phylogenetic trees seen in Figure 2, are based on 


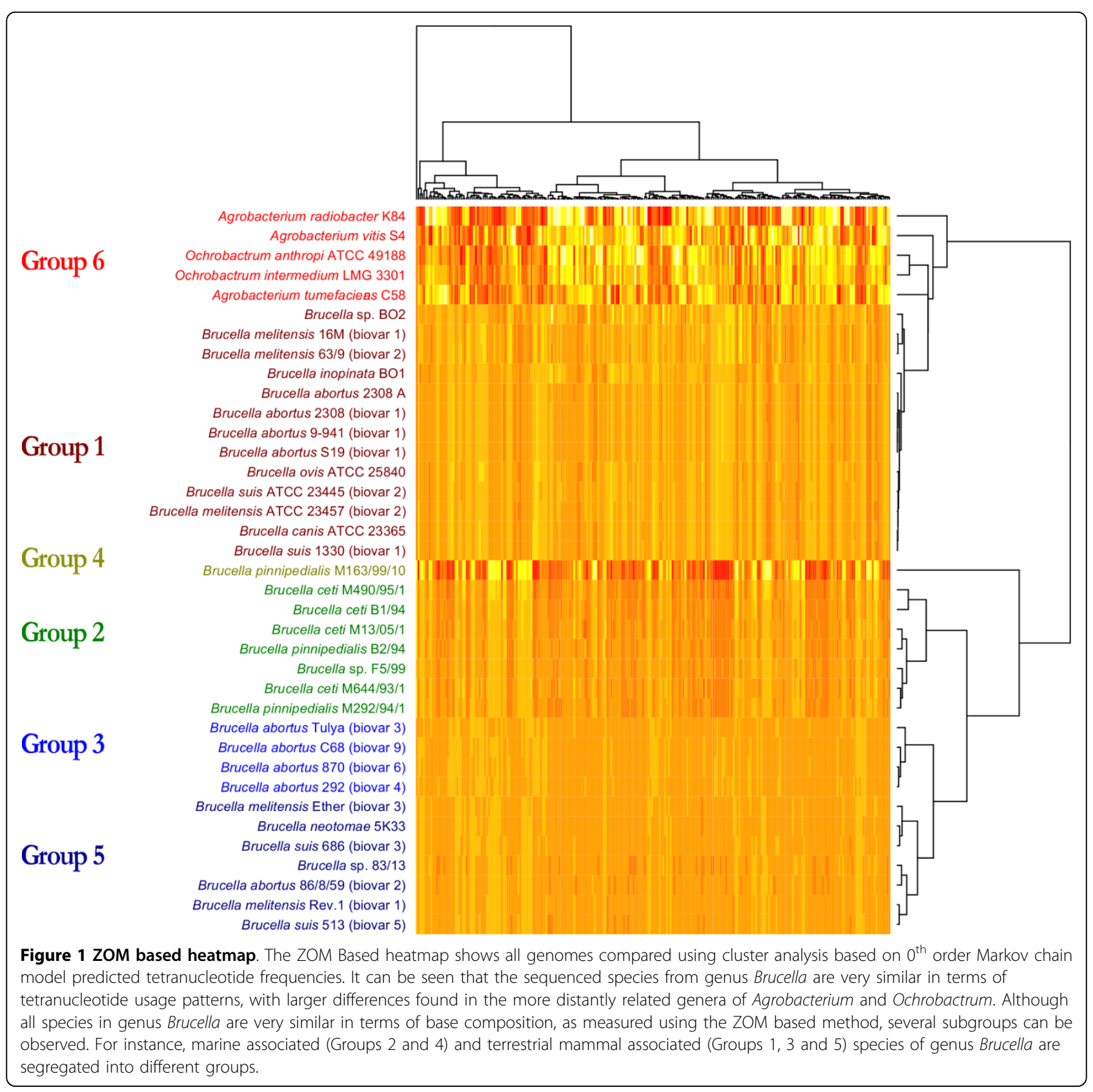

comparisons using the Pearson correlation method. The ZOM based heatmap seen in Figure 1 however, applies hierarchical clustering directly on vectors of the relative abundances of tetranucleotide frequencies (see the methods section for more details on these methods). In general, all Markov chain based models produced similar clusters, as can be seen from the color-coding in figures 1 and 2 .

From Table 1 it can be seen that the ZOM based heatmap (Figure 1) was divided into 6 groups. Groups 1 and 3 consist of Brucella species associated with terrestrial mammals, while groups 2 and 4 contain exclusively marine mammal associated species. Figure 1 shows that the only species in group 4 , B. pinnipedialis strain 163/ 99/10 isolated from a hooded seal (Cystophora cristata), shares many of the same tetranucleotide patterns with the species in group 2. Group 5 consists entirely of $B$. abortus strains; although similar in base composition to groups 1 and 3, group 5 appears to constitute a separate group. Group 6 is the most diverse group in terms of genome size, base composition, and GC content, and consists exclusively of non-Brucella species. Figure 2 shows that the species in the defined groups described in Table 1 were, for all Markov chain based genomic 
signatures, found in similar cluster groups with the exception of $B$. sp. F5/99 in group 2, which was isolated from a Pacific bottlenose dolphin (Tursiops truncatus) [21]. Although both ZOM- and FOM based methods cluster $B$. sp. F5/99 in the same group, the SOM method found the bacterium more closely related to cluster group 3.

All Markov chain based models placed B. pinnipedialis M163/99/10 in a separate group indicating relatively large genomic base compositional differences with the other Brucella species and strains (see Figure 1). $B$. abortus 2308 (biovar 1) clustered more closely to the $B$. abortus 9-941 (biovar 1) and B. abortus S19 (biovar 1) than the $B$. melitensis strains, implying that the Markov chain based models support the return to the pre-1986 taxonomy discussed above. In general, the Markov chain based genomic signatures found all members of cluster group 1 to be very similar in terms of base composition. From the viewpoint of genomic signatures, this implies that group 1 can in fact be considered as one phylogenetically coherent group. The same might be said for group 2. All Markov chain based models group the species from group 2 correspondingly; with $B$. cet $i$ M490/95/1, isolated from harbour seal (Phoca vitulina), having a somewhat larger base compositional difference than the other genomes in the group. A notable exception is $B$. sp. F5/99 that was found more similar to group 3 (rather than group 2) for the SOM based comparison method. All Markov chain based genomic signatures group the strains in cluster group 5 similarly and the species from the genera Agrobacterium and Ochrobactrum cluster separately from genus Brucella. Group 6 is thus entirely made up of species from the genera Ochrobactrum and Agrobacterium, and contains no species from genus Brucella. In Figure 2, the species from Agrobacterium and Ochrobactrum are not found in one coherent group as in Figure 1. However, a closer inspection of Figure 2 reveals that all non-Brucella species clustered separately from the Brucella species. The cluster groups were found to be so different that no reliable 
conclusion could be made as to whether the species in genus Agrobacterium or genus Ochrobactrum were more similar to the species in genus Brucella as measured with the Markov chain based models.

The ZOM based heatmap (Figure 1) shows that there are relatively large base compositional differences between genus Brucella and the genera Agrobacterium and Ochrobactrum. However, the groups resulting from the ZOM based heatmap indicate that there are large similarities between the groups containing species from genus Brucella. The genomes found in cluster group 1 appear to be very similar in terms of base composition, with only negligible differences detected between some of the genomes. The heatmap in Figure 1 also indicates that B. pinnipedialis M163/99/10 may have diverged from cluster group 2. Additionally, the tetranucleotide patterns taken from the B. pinnipedialis M163/99/10 genome resemble the other species in cluster group 2, but are more pronounced. Cluster group 5 appears to be similar to cluster group 3 in terms of tetranucleotide relative abundance patterns although some subtle differences can be observed between the different species in the group.

\section{Codon and amino acid frequencies}

The codon and amino acid frequencies based comparison methods (Figure 3 and 4) are similar to the Markov chain based models in that they are also based on oligonucleotide frequencies data. However, genomic codon and amino acid frequencies are more influenced by GC content than the Markov chain model based genomic signatures described above since no GC content or smaller oligonucleotide normalization is performed.

From Figure 3 it can be seen that the organisms making up genus Brucella form one homogeneous group with only minor frequency changes in a few of the codons. No distinction is made between terrestrial- and marine mammal associated Brucella species. The group of species not belonging to genus Brucella consists of more heterogeneous genomes in terms of codon frequencies. Figure 4 show the amino acid frequencies from the translated codon frequencies taken from the genomes of all organisms in the study. This heatmap appears to be more diverse than the codon frequencies based heatmap. However, the overall topology appears to be similar to that of Figure 3, with no distinction made between marine- and terrestrial mammal associated Brucella species. Hence, the general topology of the amino acid frequencies based heatmap appears to resemble the codon frequencies based heatmap. The resulting heatmaps from the amino acid and codon frequencies based comparisons stand in contrast to the ZOM based heatmap where a clear distinction between marine and terrestrial mammal host associated species from genus Brucella can be observed. The ZOM based heatmap appears to give a more detailed distinction between the different organisms as compared to the heatmaps based on both amino acid and codon frequencies. This is especially apparent in closely related species and strains, which are hardly distinguishable from the codon and amino acid frequencies based heatmaps. However, the codon and amino acid frequencies based cluster diagrams reinforce the impression obtained from the Markov chain models that the genomes of the species in genus Brucella have a somewhat different base composition from the species in genus Agrobacterium and genus Ochrobactrum.

\section{Proteome comparisons and the BLAST matrix}

The BLAST matrix in Figure 5 is based on all-against-all comparisons between the proteomes of all genomes discussed in the present work. More consistency, in terms of current Brucella taxonomy, was found in the BLAST matrix as compared to both the clusters based on the Markov chain based genomic signatures and codon and amino acid frequencies. This indicates that phylogenetic classification of genus Brucella based on marker genes, for instance multi locus sequence typing [22], show a surprising similarity to the organism's total gene content. Thus, at least for Brucella spp., there appears to be an association between mutations in marker genes and gene content.

The most similar species in genus Brucella in terms of gene content (or proteomes) were found to be $B$. abortus 9-941 (biovar 1) and the vaccine strain $B$. abortus S19 (biovar 1) (99.8\%, see additional file 1). O. anthropi ATCC 49188 was found to have a $48.3 \%$ proteome similarity with B. suis 1330 (biovar 1), and was the closest match between a Brucella species and a non-Brucella species. The two species from genus Ochrobactrum shared $57 \%$ of their proteins, while the most similar proteomes between two species from genus Agrobacterium, A. vitis S4 and A. tumefaciens C58, shared only $35 \%$ of their genes. For the species in genus Brucella, the poorest match based on proteome comparisons was between B. pinnipedialis M163/99/10 and B. inopinata BO1 (70\%). The most dissimilar proteomes all together, were A. radiobacter $\mathrm{K} 8$ and B. pinnipedialis M163/99/10 sharing only $21 \%$ of their genes. The most similar proteomes from the genera Agrobacterium and Brucella were A. tumefaciens C58 and B. suis 1330 (biovar 1), respectively, sharing $29 \%$ of their proteomes.

\section{Pan-genome}

Pan-genomic analysis is concerned with mapping genes that are conserved (shell) and variable (cloud) among closely related organisms, usually within a genus or species [17]. 


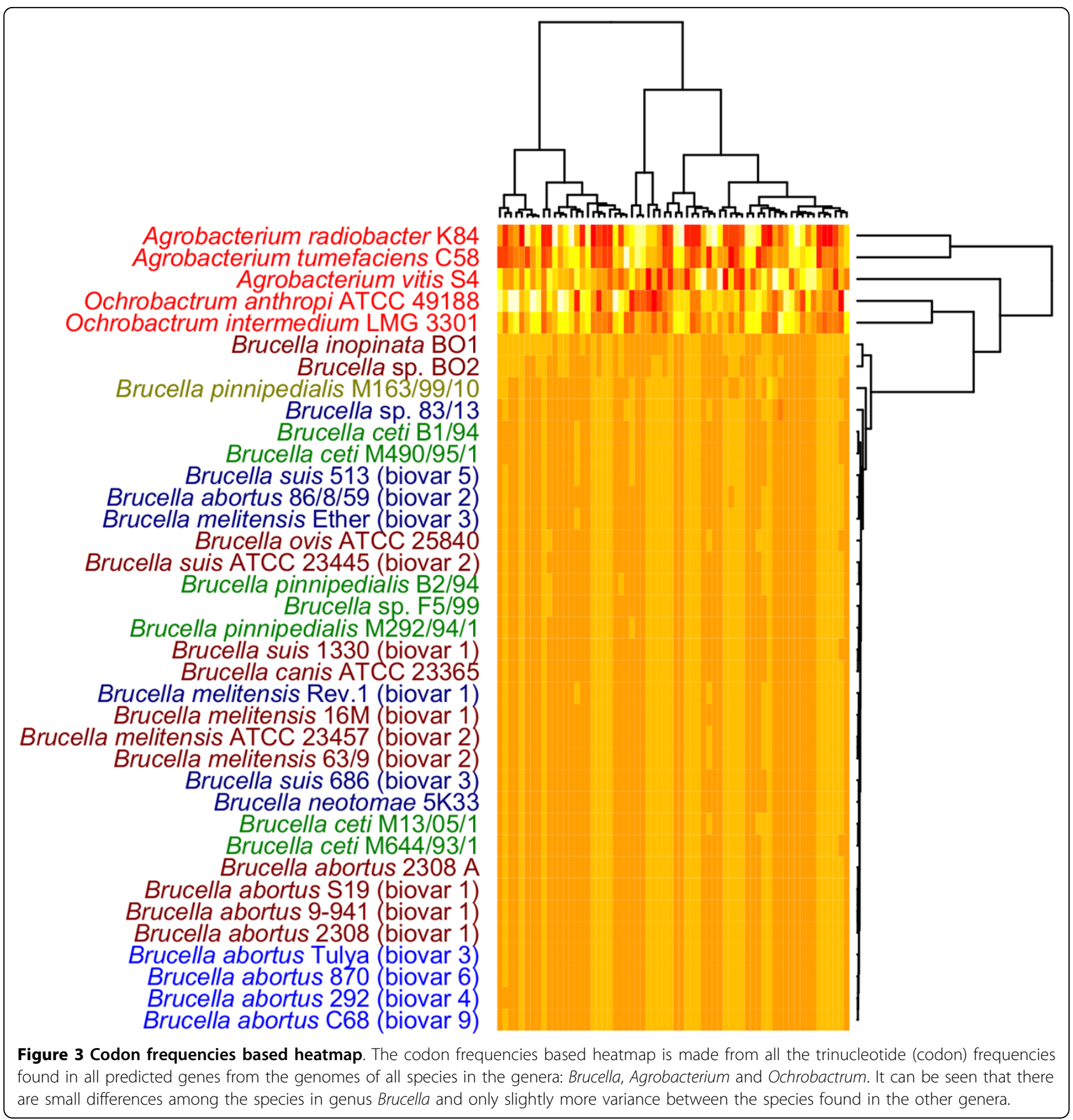

Two Brucella pan-genome trees are shown in figures 6 and 7. One emphasizing the shared shell genes (Figure 6) and the other the less conserved cloud genes (Figure $7)$. The shell genes are frequently observed in the pangenome, and differences in shell-gene content most likely reflect an evolution over a longer time span [17]. The slow divergences of orthologs have for some strains led to the complete loss of gene families. This is manifested as the bigger differences in the shell-weighted pan-genome tree. The shell tree also shows that three strains: B. sp. BO2, B. inopinata BO1 and B. sp. 83/13 differ significantly from the others. Additionally, both trees show a remarkable difference in gene content between B. pinnipedalis M163/99/10 and the other strains of the same species. The B. suis 513 (biovar 5) appears to be separated from the other B. suis strains, which may be indicative of a substantial difference in gene content. However, bootstrap support is low for most branches, which implies that the detected difference in gene content is negligible. 


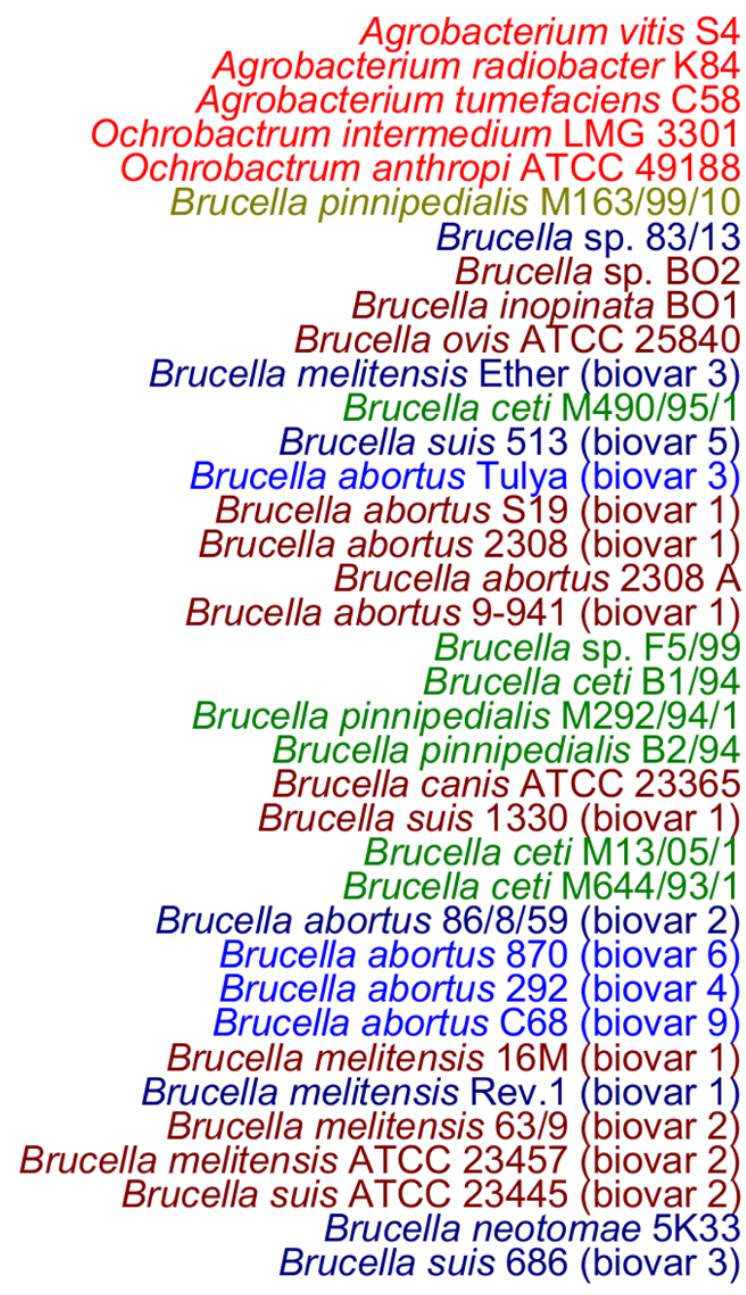

Agrobacterium vitis S4 Agrobacterium radiobacter K84 Agrobacterium tumefaciens C58 chrobactrum intermedium LMG 3301 chrobactrum anthropi ATCC 49188

Brucella sp. 83/13

Brucella sp. BO2 Brucella inopinata BO1 Brucella melitensis Ether (biovar 3 ) Brucella ceti M490/95/1 Brucella abortus Tulya (biovar 3 ) Brucella abortus S19 (biovar 1) Brucella abortus 2308 A Brucella sp. F5/99
Brucella ceti B1/94 Brucella pinnipedialis M292/94/1 Brucella pinnipedialis B2/94 Brucella canis ATCC 23365 Brucella suis 1330 (biovar 1) Brucella ceti M13/05/1 Brucella ceti M644/93/1 Brucella abortus 86/8/59 (biovar 2 ) Brucella abortus 292 (biovar 4 ) Brucella abortus C68 (biovar 9) Brucella melitensis 16M (biovar 1) Brucella melitensis Rev.1 (biovar 1) Brucella melitensis 63/9 (biovar 2) Brucella suis ATCC 23445 (biovar 2 ) Brucella suis 686 (biovar 3)

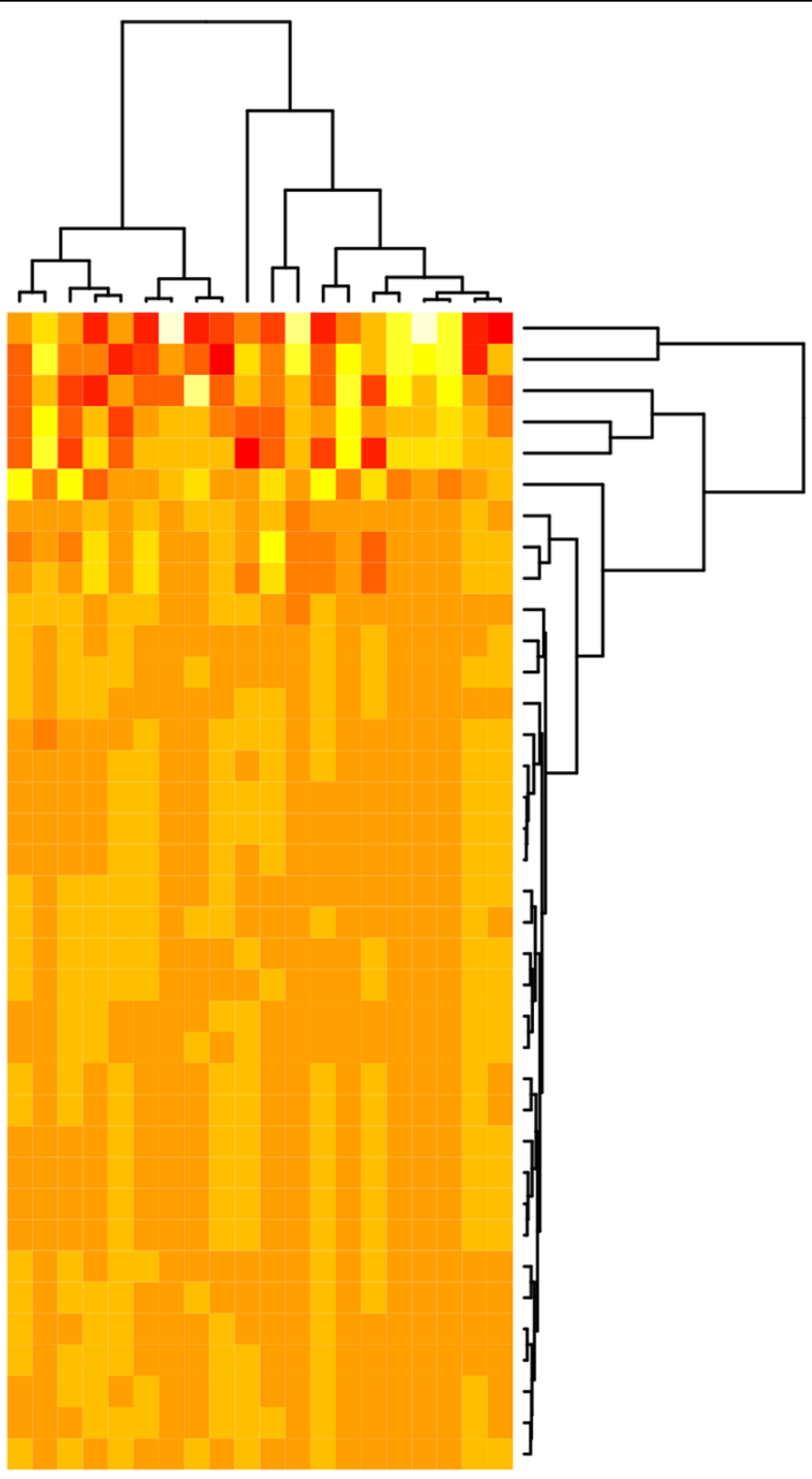

Figure 4 Amino acid cluster diagram. The amino acid frequencies based cluster diagram is made from the amino acid usage found in the predicted genes of the genomes in question. Amino acid frequencies correlate strongly with codon usage frequencies, but at a lower resolution. It can be seen that only small differences can be detected between species in genus Brucella.

The cloud weighted tree (Figure 7), which is based on promiscuous genes, shows the same overall trend that is observed for the shell tree discussed above, even though the distances between genomes have changed. The cloud genes occur rarely and may be enriched with mobile elements such as inverted repeats, insertion sequences, and transposons making them difficult to isolate as distinctive genes. The fact that the cloud tree and the shell tree show the same topology can be seen as an indication that gene uptake from more distantly related organisms is rare in genus Brucella.

The pan-genomic analyses conducted here (figures 6, 7 and 8) reveal that there appears to be little genetic exchange within the sequenced species from genus $\mathrm{Bru}$ cella. Compared to other bacteria, the present analyses of Brucella spp. uncovers greater homogeneity in terms of shared gene content than other species, such as Streptococcus spp. [16], E. coli spp.[23] and Burkholderia spp. [15]. In line with the BLAST matrix, the shell and cloud 


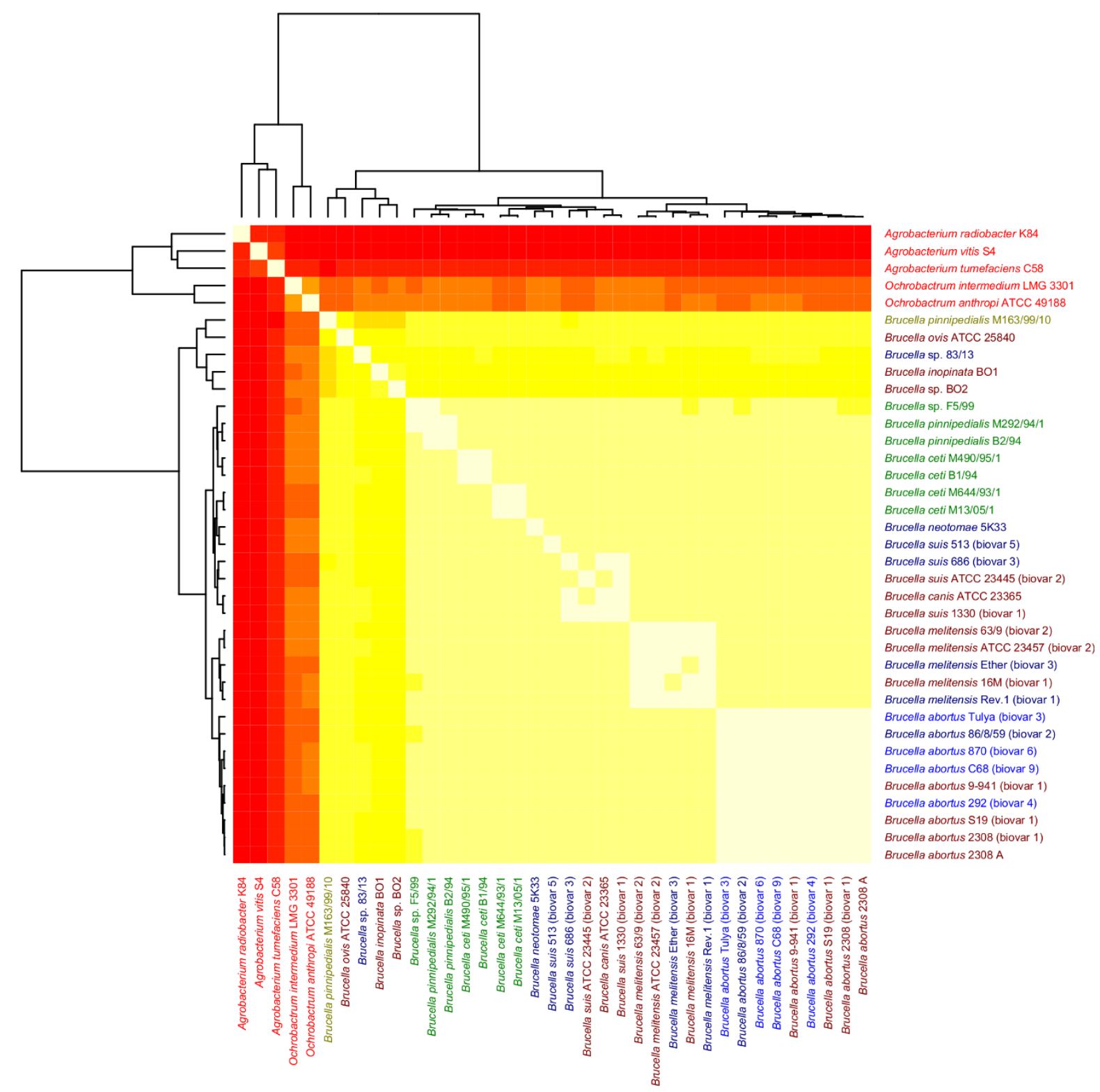

Figure 5 BLAST matrix. Genomes are compared gene-wise using BLAST. All genes were converted to proteins and compared pair-wise allagainst-all for each genome. Lighter color means closer similarity. Paralogs are removed when genomes are compared to them self which means that the hit score is less than $100 \%$.

trees (figures 6 and 7, respectively) showed a remarkable consistency to current Brucella taxonomy. Only minor rearrangements were detected between the shell and cloud trees, with the departing of $B$. sp. F5/99 from the group of marine mammal associated species as the most notable exception. This may indicate that the sequenced genomes from genus Brucella are strongly conserved since differences in the potentially mobile genes described by the cloud tree are in accordance with the shell tree consisting of more conserved genes shared by all members in genus Brucella. Although DNA uptake from the environment and distantly related organisms occur in genus Brucella $[24,25]$, it may be relatively rare otherwise it is expected that larger rearrangements would have been observed in the cloud tree [23].

\section{Discussion}

Markov chain based genomic signatures

The oligonucleotide frequencies based models discussed in the present work are not affected by genomic rearrangements since estimations are based on oligonucleotide frequencies from all DNA sequences available. 


\section{Shell weighted}

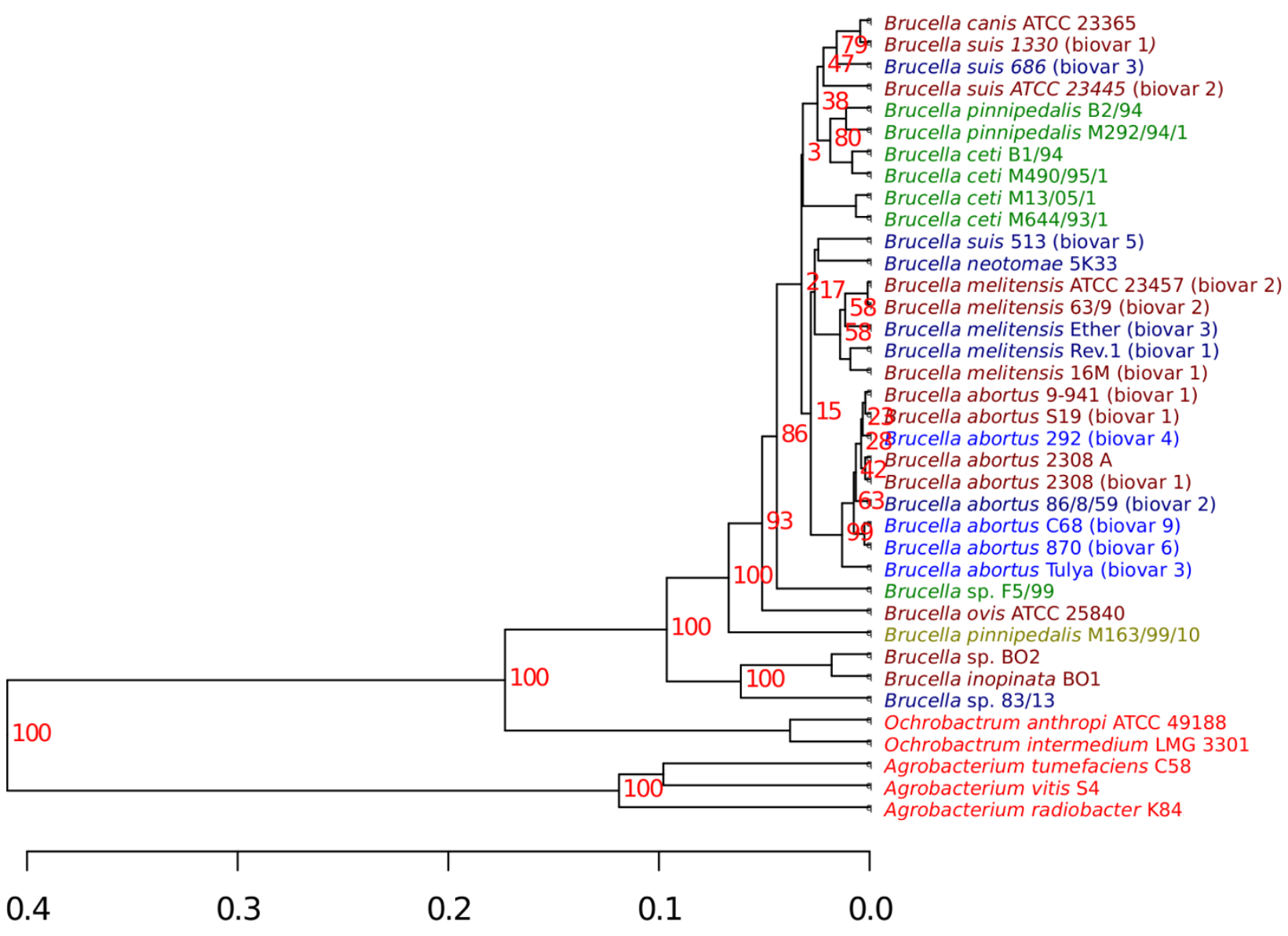

\section{Relative manhattan distance}

Figure 6 Pan-genomic shell tree. The Figure shows a pan-genomic tree based on a weighting strategy emphasizing 'shell' genes. The red numbers are bootstrap-values, in percentage, based on 100 bootstrap samples.

Differences between organisms, as measured using the oligonucleotide frequencies based methods, are therefore due to changes in base composition at the genome level caused first and foremost by mutational bias and to a lesser degree by possible horizontal transfer or DNA uptake [12]. Since the Markov chain based genomic signatures are normalized with respect to GC content and smaller oligonucleotides, they reflect a stronger degree of 'inertia' than the amino acid and codon frequencies based methods.

Our results, obtained using the Markov chain based genomic signatures, differ from the taxonomic assessments based on singular marker genes from multi locus sequencing [22]. This could be due to the low resolution of the Markov chain models or, alternatively, due to the genomic properties reflected by these methods. The ZOM based clusters have been shown to be sensitive to environmental conditions as well as phylogeny [26]. The reliability of methods based on equal probability of mutations throughout an entire genome, like all oligonucleotide based methods discussed here, must also be questioned. As sequencing of the genomes of organisms is increasing, more information is gained casting doubts about the validity of the molecular clock hypothesis [27].

\section{Comparisons based on codon and amino acid frequencies} The ZOM, codon frequencies and amino acid frequencies based cluster diagrams (figures 1,3 and 4) group the species in genus Brucella different than the gene based methods (figures 5, 6 and 7). This may indicate that conflicting evolutionary forces are driving mutational bias and gene content in genus Brucella. Codon and amino acid frequencies are remarkably similar for Brucella spp. compared to the species in the genera 


\section{Cloud weighted}

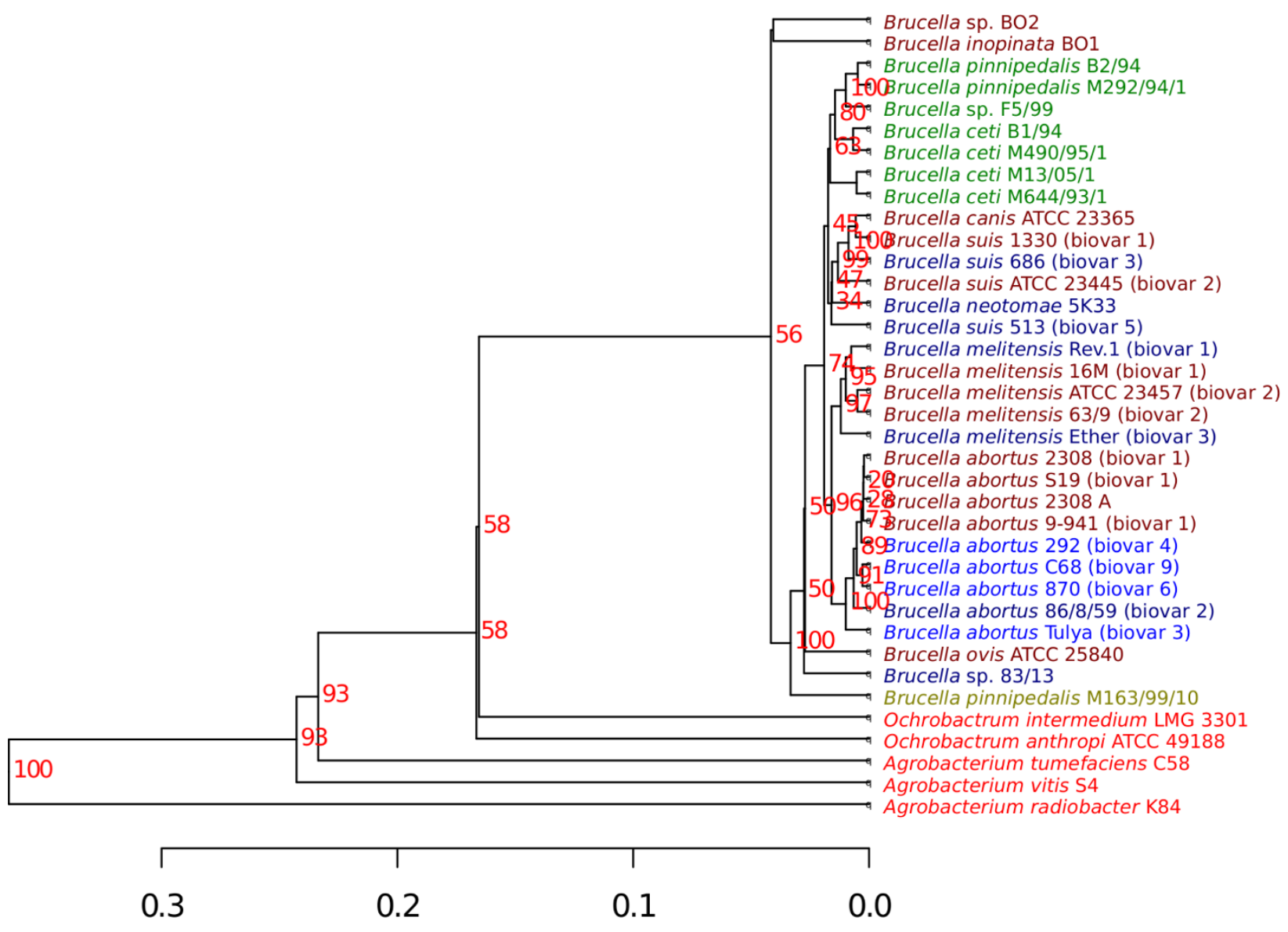

\section{Relative manhattan distance}

Figure 7 Pan-genomic cloud tree. The Figure shows a pan-genomic tree based on a weighting strategy emphasizing 'cloud' genes. The red numbers are bootstrap-values, in percentage, based on 100 bootstrap samples.

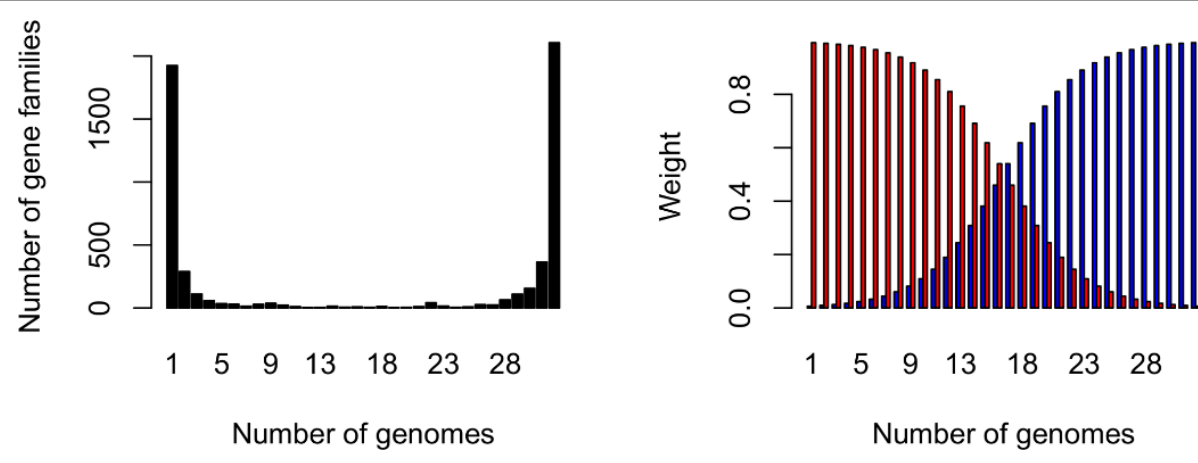

Figure 8 Weighted pan-genomes. The left panel is a bar-chart showing the number of gene families observed in 1, 2, ..., 32 gene families within the Brucella pan-genome (only genomes from species in genus Brucella are included). The gene families only found in a few genomes (left-wing bars) are called cloud genes, and those found in most genomes (right-wing bars) are called shell genes. The core genes are those that are found in all genomes (rightmost bar). The right panel indicates two different weighting strategies for computing the pan-genome tree. The red bars give more weight to cloud genes when comparing two genomes, while the blue bars emphasize the shell genes. 
Agrobacterium and Ochrobactrum. The lack of consistency between the codon and amino acid frequencies based heatmaps on one side and the ZOM based heatmap on the other, may be due to a stronger phylogenetic signal found in the $0^{\text {th }}$ order Markov chain based model $[28,29]$. While the species in genus Brucella isolated from marine mammals formed one homogeneous group in the dendrograms produced by the Markov chain based genomic signatures, no such clustering could be detected with the codon and amino acid frequencies based heatmaps. Codon frequencies, which are highly affected by genomic GC content, will in turn affect amino acid frequencies [13].

\section{Evolutionary indications}

Studies show that bacteria, which conform to an intracellular lifestyle, tend to become more AT rich [30,31]. Mutations have a tendency to go from $\mathrm{G}$ and $\mathrm{C}$ to $\mathrm{A}$ and $T$ [32]. Mutations in genes will lead to genes that are non-expressible and eventually lost resulting in a reduced genome size [30]. AT content is associated with genome size in bacteria, where AT rich genomes tend to be smaller than GC rich genomes [33-35]. Table 1 shows that the marine mammal associated Brucella spp. are more GC rich than their terrestrial mammal based counterparts. In addition, assuming that the sizes of the non-assembled genomes are approximately correct, the marine mammal associated species in genus Brucella appear to have, on average, slightly larger genomes than the terrestrial mammal associated species. A possible scenario therefore, assuming a hypothetical ancestor X for both marine and terrestrial mammal Brucella spp., is that the marine mammal species of genus Brucella are closer to $\mathrm{X}$ than the terrestrial mammal associated species. One possible explanation for this is that the terrestrial mammal associated species have been living longer with their hosts than their marine mammal based relatives. The most GC rich genome of all Brucella spp. is the genome of $B$. pinnipedialis M163/99/10. It is therefore tempting to speculate that the hypothetical ancestor $\mathrm{X}$ could have a genome that is more similar to the marine mammal associated strain. The most AT rich genome from genus Brucella examined in this study is $B$. ovis ATCC 25840. From the perspective that intracellular bacteria tend to become more AT rich [30], it is possible that the genome of B. ovis ATCC 25840 is the least similar, in terms of base composition, to the hypothetical ancestor X of all species in genus Brucella examined here. It should be noted that the idea that $B$. pinnipedialis M163/99/10 is the last descendant from X rests on the assumption that genomes from intracellular bacteria become progressively smaller and more AT rich [25]. Buchnera aphidicola, Mycobacterium leprae and Sodalis glossinidius are examples of microbes all presumed to have adapted to an intra-cellular environment with the consequences of increased AT richness and genome reduction [30,36,37]. The cyanobacterium Prochlorococcus marinus MED4 provides an interesting example of a free-living bacterium, not associated with any host, becoming more AT rich and having undergone genome reduction possibly due to adaption to an environment with less nutrients available [38].

We emphasize again that the scenario described above is only one possible explanation. An alternative assertion to the genome reduction hypothesis is that species found in similar environments tend to have genomes with similar AT content regardless of phylogenetic relationship $[39,40]$. Therefore, the difference in AT content between the marine and terrestrial mammal Brucella strains may be a consequence of environmental differences.

\section{Gene based comparisons}

The remarkable consistency between the proteome based comparisons and current Brucella taxonomy differs from the DNA based methods. Therefore, the congruent shell and cloud trees suggest that DNA uptake from species outside genus Brucella is an infrequent event, at least for the sequenced genomes included in this study. This is also supported by SNP analysis, which indicate that DNA exchange is fairly uncommon in genus Brucella [10]. Since the phylogeny recreated by the pan-genomic analyses resemble the pair-wise BLAST comparisons, it appears that gene similarity in the species of genus Brucella is concordant to current taxonomy based on marker genes and similar methods [9]. This implies that any mutation in the marker genes may be indirectly linked to gene gain or loss in genus Brucella. The difference in results obtained using the oligonucleotide based methods and the gene based methods suggest that the genomic properties reflected by the respective methods represent different perspectives. In previous work, we found that the ZOM based method is associated with a set of genomic properties including environment and phylogeny [26]. The ZOM based method is therefore a more composed method than the marker gene based comparison methods, in the sense that the ZOM heatmap topology is determined from a multitude of genomic properties.

The close resemblance found between the marker gene based phylogeny on one hand and the proteome based phylogeny on the other may thus be an indication that the mutations in the marker genes are somehow connected to gene loss or gain. In contrast to the result obtained with the Markov chain based genomic signatures, the differences in gene content in genus Brucella seem to be in accordance with a genome-wide molecular clock [41]. 
All species in genus Agrobacterium and genus Ochrobactrum are, in general, different from the species in genus Brucella both in terms of the oligonucleotide based methods and the gene based methods. The closest match in terms of gene content between a genome of a species from genus Brucella and a non-Brucella species was found to be between B. suis 1330 (biovar 1) and $O$. anthropi ATCC 49188, having a gene similarity of $48 \%$. All genomes of the species in genus Brucella showed a gene content similarity of more than $70 \%$. This raises again the question whether the genomes of the species in genus Brucella discussed in the present work should be divided into different species rather than strains. Such a scenario would imply that the members of genus Ochrobactrum would join genus Brucella, while the present species in genus Brucella would all be one species, but different subspecies or strains. For instance, the two genomes of the two species in genus Ochrobactrum discussed here were found to share only $57 \%$ of their genes, and the most similar genomes of genus Agrobacterium shared only $35 \%$ of their genes. Thus, based on the methods described in this work, there are many aspects that must be taken into consideration when taxonomy and phylogeny is to be decided.

\section{Conclusions}

We find that the ZOM based heatmap is superior to both the codon and amino acid frequencies based heatmaps at distinguishing between closely related species and strains. The Markov chain based genomic signatures appear to have a higher resolution than the codon frequencies. The codon frequencies have a higher resolution than the amino acid frequencies. The amino acid frequencies between the genomes however, appear to be more diverse than the codon frequencies. Figure 2 shows that the differences between the different Markov chain models is small.

The proteome based comparisons, i.e. the BLAST matrix and pan-genomic analyses, differ somewhat from the base composition based methods, i.e. Markov chain based genomic signatures and codon and amino acid frequencies based methods, in terms of species classification. The BLAST matrix, based on pair-wise gene comparisons between the genomes of all microbes support the present Brucella taxonomy remarkably well suggesting a correlation between marker gene based phylogeny and the proteomes in genus Brucella. The pan-genomic analyses, including both shell and cloud weighted trees, also support the present Brucella taxonomy suggesting, in addition, infrequent horizontal transfer between species from genus Brucella and organisms belonging to other genera.

Comparing the pan-genomic trees to the base compositional based Markov chain models and codon and amino acid frequencies based methods, it can be concluded that subtle differences can be found below protein level. While there appears to be a fairly conserved gene pool in genus Brucella, more differences can also be found at the nucleotide level using the Markov chain based genomic signatures, which appeared to group the different species more strongly according to environment.

\section{Methods}

All genomes were downloaded from Genbank [http:// www.ncbi.nlm.nih.gov/genomes/lproks.cgi], the PATRIC website [42] [http://patric.vbi.vt.edu/] and the Broad Institute [http://www.broadinstitute.org/annotation/genome/brucella_group/MultiHome.html]. All genomes consisting of two chromosomes were concatenated into one file for each genome. All oligonucleotide based analyses were carried out in the 5'-3' direction for each genome (see $[43,44]$ for justification of this). All statistical and mathematical analyses were carried out using the program R [45].

\section{Genomic signatures based on the $0^{\text {th }}, 1^{\text {st }}$ and $2^{\text {nd }}$ order Markov chain models}

The $0^{\text {th }}, 1^{\text {st }}$ and $2^{\text {nd }}$ order Markov chain model based genomic signatures, referred to here respectively as ZOM, FOM and SOM based models, are different methods used to compare genomes by estimating the total difference between observed and approximated tetranucleotide frequencies. A thorough explanation of the different Markov chain model based genomic signatures can be found in [12]. Therefore, only a brief explanation of the notation used and a superficial introduction will be given below.

The heatmap based on the $0^{\text {th }}$ order Markov chain model This heatmap (Figure 1), referred to as the ZOM-heatmap, is based on pair-wise comparisons using the $0^{\text {th }}$ order Markov chain model $([12,26,44])$. Tetranucleotide frequencies are estimated for all genomes and normalized with respect to the corresponding nucleotide frequencies:

$$
\rho_{X Y Z W}(f)=\frac{f_{X Y Z W}}{f_{X} f_{Y} f_{Z} f_{W}}
$$

A vector, consisting of the relative abundances found using Equation (1) from all possible tetranucleotide combinations $\left(4^{4}=256\right)$, is created for each genome. These vectors were clustered using average linkage hierarchical clustering with the Euclidean distance measure.

\section{Dendrograms based on $0^{\text {th }}, 1^{\text {st }}$ and $2^{\text {nd }}$ order Markov property based genomic signatures}

Tetranucleotide frequencies are approximated from genomic data according to the Markov chain based 
genomic signature model used. ZOM based genomic signatures approximate genomic tetranucleotide frequencies using genomic mononucleotide frequencies as described by Equation (1) above. FOM based signatures approximate genomic tetranucleotide frequencies using a combination of both genomic mono- and dinucleotide frequencies.

$$
\xi_{X Y Z W}(f)=\frac{f_{Y} f_{Z} f_{X Y Z W}}{f_{X Y} f_{Y Z} f_{Z W}}
$$

SOM based genomic signatures approximate genomic tetranucleotide frequencies using genomic di- and trinucleotide frequencies:

$$
\eta_{X Y Z W}(f)=\frac{f_{X Y Z W} f_{Y Z}}{f_{X Y Z} f_{Y Z W}}
$$

Instead of the average absolute distance measure used by Karlin and others [46-48] for pair-wise comparisons, we use the Pearson correlation measure for all signature based methods discussed above to compare two DNA sequences:

$$
\begin{gathered}
\operatorname{Cor}_{\xi}(f, g)=\frac{\sum_{X Y Z W}\left[\left(\xi_{X Y Z W}(f)-\overline{\xi_{X Y Z W}(f)}\right)\right.}{\sqrt{\sum_{X Y Z W}\left(\xi_{X Y Z W}(f)-\overline{\xi_{X Y Z W}(f)}\right)^{2}}} \times \\
\times \frac{\left.\left(\xi_{X Y Z W}(g)-\overline{\xi_{X Y Z W}(g)}\right)\right]}{\sqrt{\sum_{X Y Z W}\left(\xi_{X Y Z W}(g)-\overline{\xi_{X Y Z W}(g)}\right)^{2}}}
\end{gathered}
$$

This formula gives the standard Pearson correlation coefficient between two DNA sequences $f$ and $g$, using the FOM based genomic signature, i.e. $\xi_{X Y Z W}$. Two identical sequences will result in a value of 1 , while two completely different sequences will result in a value of 0 . For instance, by comparing the DNA sequence of a bacterial genome to a completely random DNA sequence, with similar GC content, will result in a value very close to 0 .

To create the phylogenetic trees, all genomes were compared pair-wise using the Pearson correlation measure (Equation (4)) with the ZOM, FOM and SOM based methods. The resulting ZOM, FOM and SOM correlation matrices, obtained from the pair-wise comparisons, are then clustered using hierarchical clustering. Average linkage was used as the clustering method to make the clustering as unbiased as possible. Because the difference between genomes, as measured using the Markov chain model based genomic signatures, was specified using the Pearson correlation coefficient, the Manhattan method was used as the distance measure.
The codon and amino acid frequencies based heatmaps The codon frequencies are based on overlapping trinucleotide frequencies in open reading frames predicted for all genomes. The open reading frames were predicted using the Prodigal gene finder [14]. Vectors of codon and amino acid frequencies, similar to the $0^{\text {th }}$ order Markov chain model discussed above, were calculated for every genome. The amino acid based heatmap was created using vectors containing amino acid frequencies from all converted open reading frames in each genome. The clustering method used for the frequency vectors of both codons and amino acids was identical to the clustering method used to generate the ZOM based heatmap, i.e. hierarchical clustering based on Manhattan distance and average linkage.

\section{The BLAST matrix proteome comparisons}

Genes were predicted from the selected genomes using the Prodigal gene finder [14]. A BLAST matrix was constructed by performing pair-wise gene comparisons using BLAST for all genomes [15,49]. Based on these results, sequences were clustered into gene families according to the 'fifty-fifty' rule, i.e. two sequences are in the same family if the best local alignment between them cover at least $50 \%$ of the length of both sequences and also contain at least $50 \%$ identities ([16]). When a genome is compared to itself using BLAST paralogs are excluded. Thus, a genome compared to it self will seldom match $100 \%$ since the paralogs are not included.

\section{Pan-genomics}

Gene families were computed as described above for the BLAST matrix. The presence or absence of gene families was stored as a pan-matrix $M$, where each row $i$ corresponds to a gene family and each column $j$ a genome. Then, if gene family $i$ is present in genome $j, M_{i j}=1$, if not $M_{i j}=0$.

The presence or absence of pan-genome gene families can be used to give a high-resolution clustering of genomes. We have constructed a pan-genome tree based on relative Manhattan distances between genomes, computed from the pan-matrix. The distance between the genomes $l$ and $k$ is simply the fraction of gene families where their presence or absence status differs [50]. When computing this distance, some genes may be given less weight than others, i.e. disagreement in presence or absence status is more important for some types of genes [51]. When considering pan-genomes we propose the weightings shown in Figure 8. The shell genes are the gene families often observed among the genomes, while the cloud genes are rarely observed [52]. Both shell and cloud type of genes can be emphasized by the weighting strategies shown in Figure 8 . 


\section{Additional material}

Additional file 1: An Excel file containing the BLAST matrix showing percentage of proteome similarity resulting from the all-against-all comparisons of the genomes discussed in the study. This percentage table was used to produce the heatmap in Figure 5.

\section{Acknowledgements}

All authors wish to extend their gratitude to the PATRIC and Broad Institute websites for providing us access to their Brucella/Ochrobactrum genomes. Eystein Skjerve and Bekele Megersa are also thanked for helpful suggestions and comments. Colleen Ussery is acknowledged for critically drafting and revising the manuscript.

\section{Author details}

${ }^{1}$ Norwegian School of Veterinary Science, Department of Food Safety and Infection Biology, Epicenter, Ullevålsveien 72, PO Box 8146 Dep, NO-0033 Oslo, Norway. ${ }^{2}$ Norwegian University of Life Sciences, Department of Chemistry, Biotechnology and Food Sciences, Ås, Norway. ${ }^{3}$ INRA, UR1282, Infectiologie Animale et Santé Publique, IASP, Nouzilly, F-37380, France. ${ }^{4}$ University of Oslo, Department of Informatics, Pb. 1080, 0316 Oslo, Norway. ${ }^{5}$ Center for Biological Sequence Analysis, Department of Systems Biology, Comparative genomics unit, Technical University of Denmark, DK-2800 Lyngby, Denmark. ${ }^{6}$ National Veterinary Institute, Section for epidemiology, $\mathrm{Pb}$ 750 Sentrum, N-0106 Oslo, Norway. ${ }^{7}$ Norwegian School of Veterinary Science, Department of Food Safety and Infection Biology, Section of Arctic Veterinary Medicine, Stakkevollveien 23, 9016 Troms $\varnothing$, Norway.

\section{Authors' contributions}

$\mathrm{JB}$ wrote the paper and conducted the base compositional analyses; LS performed the pan-genomic analyses and together with $\mathrm{KL}$ carried out the protein based analyses. JB, AC and JG analyzed the data and related the findings to Brucella taxonomy. JB, LS and ABK carried out mathematical/ statistical analyses. JB, AC, JG and DU analyzed the data, and drafted and revised the manuscript. The project was initiated by JG. All authors have read and approved the final manuscript.

Received: 16 March 2010 Accepted: 13 August 2010

Published: 13 August 2010

\section{References}

1. Whatmore AM: Current understanding of the genetic diversity of Brucella, an expanding genus of zoonotic pathogens. Infect Genet Evol 2009, 9(6):1168-84

2. Verger J, Grimont F, Grimont PAD, Grayon M: Brucella, a Monospecific Genus as Shown by Deoxyribonucleic Acid Hybridization. Int J Syst Bacteriol 1985, 35(3):292-295.

3. Osterman B, Moriyon I: International Committee on Systematics of Prokaryotes; Subcommittee on the taxonomy of Brucella: Minutes of the meeting, 17 September 2003, Pamplona, Spain. Int J Syst Evol Microbiol 2006, 56(5):1173-1175.

4. Foster G, Osterman BS, Godfroid J, Jacques I, Cloeckaert A: Brucella ceti sp. nov. and Brucella pinnipedialis sp. nov. for Brucella strains with cetaceans and seals as their preferred hosts. Int J Syst Evol Microbiol 2007, 57(Pt 11):2688-2693.

5. Scholz HC, Hubalek Z, Sedlacek I, Vergnaud G, Tomaso H, Al Dahouk S, Melzer F, Kampfer P, Neubauer H, Cloeckaert A, Maquart M, Zygmunt MS, Whatmore AM, Falsen E, Bahn P, Gollner C, Pfeffer M, Huber B, Busse HJ, Nockler K: Brucella microti sp. nov., isolated from the common vole Microtus arvalis. Int J Syst Evol Microbiol 2008, 58(Pt 2):375-382.

6. Scholz HC, Nockler K, Gollner C, Bahn P, Vergnaud G, Tomaso H, AlDahouk S, Kampfer P, Cloeckaert A, Maquart M, Zygmunt MS, Whatmore AM, Pfeffer M, Huber B, Busse HJ, De BK: Brucella inopinata sp. nov., isolated from a breast implant infection. Int J Syst Evol Microbiol 2010, 60(Pt 4):801-8.

7. DelVecchio VG, Kapatral V, Redkar RJ, Patra G, Mujer C, Los T, Ivanova N, Anderson I, Bhattacharyya A, Lykidis A, Reznik G, Jablonski L, Larsen N,
D'Souza M, Bernal A, Mazur M, Goltsman E, Selkov E, Elzer PH, Hagius S, O'Callaghan D, Letesson JJ, Haselkorn R, Kyrpides N, Overbeek R: The genome sequence of the facultative intracellular pathogen Brucella melitensis. Proc Natl Acad Sci USA 2002, 99(1):443-448.

8. Paulsen IT, Seshadri R, Nelson KE, Eisen JA, Heidelberg JF, Read TD, Dodson RJ, Umayam L, Brinkac LM, Beanan MJ, Daugherty SC, Deboy RT, Durkin AS, Kolonay JF, Madupu R, Nelson WC, Ayodeji B, Kraul M, Shetty J, Malek J, Van Aken SE, Riedmuller S, Tettelin H, Gill SR, White O, Salzberg SL, Hoover DL, Lindler LE, Halling SM, Boyle SM, Fraser CM: The Brucella suis genome reveals fundamental similarities between animal and plant pathogens and symbionts. Proc Natl Acad Sci USA 2002, 99(20):13148-13153.

9. Moreno E, Cloeckaert A, Moriyon I: Brucella evolution and taxonomy. Vet Microbiol 2002, 90(1-4):209-227.

10. Foster JT, Beckstrom-Sternberg SM, Pearson T, Beckstrom-Sternberg JS, Chain PS, Roberto FF, Hnath J, Brettin T, Keim P: Whole-genome-based phylogeny and divergence of the genus Brucella. J Bacteriol 2009, 191(8):2864-2870.

11. Coenye T, Gevers D, Van de PY, Vandamme P, Swings J: Towards a prokaryotic genomic taxonomy. FEMS Microbiol Rev 2005, 29(2):147-167.

12. Bohlin J, Skjerve E: Examination of genome homogeneity in prokaryotes using genomic signatures. PLoS One 2009, 4(12):e8113.

13. Willenbrock $H$, Friis $C$, Juncker AS, Ussery DW: An environmental signature for 323 microbial genomes based on codon adaptation indices. Genome Biol 2006, 7(12):R114

14. Hyatt $D$, Chen GL, Locascio PF, Land ML, Larimer FW, Hauser LJ: Prodigal: prokaryotic gene recognition and translation initiation site identification. BMC Bioinformatics 2010, 11(1):119.

15. Ussery DW, Kiil K, Lagesen K, Sicheritz-Ponten T, Bohlin J, Wassenaar TM: The Genus Burkholderia: Analysis of 56 Genomic Sequences. Genome Dyn 2009, 6:140-157.

16. Tettelin H, Masignani V, Cieslewicz MJ, Donati C, Medini D, Ward NL, Angiuoli SV, Crabtree J, Jones AL, Durkin AS, Deboy RT, Davidsen TM, Mora M, Scarselli M, Ros IMY, Peterson JD, Hauser CR, Sundaram JP, Nelson WC, Madupu R, Brinkac LM, Dodson RJ, Rosovitz MJ, Sullivan SA, Daugherty SC, Haft DH, Selengut J, Gwinn ML, Zhou LW, Zafar N, Khouri H, Radune D, Dimitrov G, Watkins K, O'Connor KJB, Smith S, Utterback TR, White O, Rubens CE, Grandi G, Madoff LC, Kasper DL, Telford JL, Wessels MR, Rappuoli R, Fraser CM: Genome analysis of multiple pathogenic isolates of Streptococcus agalactiae: Implications for the microbial "pan-genome". 2005, 102(39):13950-13955.

17. Snipen L, Almoy T, Ussery DW: Microbial comparative pan-genomics using binomial mixture models. BMC Genomics 2009, 10:385.

18. Scholz HC, Al Dahouk S, Tomaso H, Neubauer H, Witte A, Schloter M, Kampfer P, Falsen E, Pfeffer M, Engel M: Genetic diversity and phylogenetic relationships of bacteria belonging to the OchrobactrumBrucella group by recA and 16S rRNA gene-based comparative sequence analysis. Syst Appl Microbiol 2008, 31(1):1-16.

19. Chen SL, Lee W, Hottes AK, Shapiro L, McAdams HH: Codon usage between genomes is constrained by genome-wide mutational processes. Proc Natl Acad Sci USA 2004, 101(10):3480-3485.

20. Tsolis RM, Seshadri R, Santos RL, Sangari FJ, Lobo JM, de Jong MF, Ren Q, Myers G, Brinkac LM, Nelson WC, Deboy RT, Angiuoli S, Khouri H, Dimitrov G, Robinson JR, Mulligan S, Walker RL, Elzer PE, Hassan KA, Paulsen IT: Genome degradation in Brucella ovis corresponds with narrowing of its host range and tissue tropism. PLOS One 2009, 4(5): e5519.

21. Ewalt DR, Payeur JB, Martin BM, Cummins DR, Miller WG: Characteristics of a Brucella species from a bottlenose dolphin (Tursiops truncatus). I Vet Diagn Invest 1994, 6(4):448-452.

22. Whatmore AM, Perrett LL, MacMillan AP: Characterisation of the genetic diversity of Brucella by multilocus sequencing. BMC Microbiol 2007, 7:34.

23. Willenbrock $\mathrm{H}$, Hallin PF, Wassenaar TM, Ussery DW: Characterization of probiotic Escherichia coli isolates with a novel pan-genome microarray. Genome Biol 2007, 8(12):R267.

24. Rajashekara G, Glasner JD, Glover DA, Splitter GA: Comparative wholegenome hybridization reveals genomic islands in Brucella species. J Bacteriol 2004, 186(15):5040-5051.

25. Wattam AR, Williams KP, Snyder EE, Almeida NF Jr, Shukla M, Dickerman AW, Crasta OR, Kenyon R, Lu J, Shallom JM, Yoo H, Ficht TA, Tsolis RM, Munk C, Tapia R, Han CS, Detter JC, Bruce D, Brettin TS, 
Sobral BW, Boyle SM, Setubal JC: Analysis of ten Brucella genomes reveals evidence for horizontal gene transfer despite a preferred intracellular lifestyle. J Bacteriol 2009, 191(11):3569-3579.

26. Bohlin J, Skjerve E, Ussery DW: Analysis of genomic signatures in prokaryotes using multinomial regression and hierarchical clustering. BMC Genomics 2009, 10:487.

27. Kuo $\mathrm{CH}$, Ochman H: Inferring clocks when lacking rocks: the variable rates of molecular evolution in bacteria. Biol Direct 2009, 4:35.

28. Karlin S, Burge C: Dinucleotide relative abundance extremes: a genomic signature. Trends Genet 1995, 11(7):283-290.

29. Teeling H, Meyerdierks A, Bauer M, Amann R, Glockner FO: Application of tetranucleotide frequencies for the assignment of genomic fragments. Environ Microbiol 2004, 6(9):938-947.

30. Moran NA: Microbial minimalism: genome reduction in bacterial pathogens. Cell 2002, 108(5):583-586.

31. Rocha EP, Danchin A: Base composition bias might result from competition for metabolic resources. Trends Genet 2002, 18(6):291-294.

32. Worning P, Jensen LJ, Hallin PF, Staerfeldt HH, Ussery DW: Origin of replication in circular prokaryotic chromosomes. Environ Microbiol 2006, 8(2):353-361.

33. Mitchell D: GC content and genome length in Chargaff compliant genomes. Biochem Biophys Res Commun 2007, 353(0006-291; 1):207-210.

34. Musto H, Naya H, Zavala A, Romero H, varez-Valin F, Bernardi G: Genomic GC level, optimal growth temperature, and genome size in prokaryotes. Biochem Biophys Res Commun 2006, 347(0006-291; 1):1-3.

35. Bohlin J, Skjerve E, Ussery DW: Investigations of oligonucleotide usage variance within and between prokaryotes. PLoS Comput Biol 2008, 4(4): e1000057.

36. Gomez-Valero L, Rocha EP, Latorre A, Silva FJ: Reconstructing the ancestor of Mycobacterium leprae: the dynamics of gene loss and genome reduction. Genome Res 2007, 17(8):1178-1185.

37. Toh H, Weiss BL, Perkin SA, Yamashita A, Oshima K, Hattori M, Aksoy S: Massive genome erosion and functional adaptations provide insights into the symbiotic lifestyle of Sodalis glossinidius in the tsetse host. Genome Res 2006, 16(2):149-156.

38. Dufresne A, Garczarek L, Partensky F: Accelerated evolution associated with genome reduction in a free-living prokaryote. Genome Biol 2005, 6(2):R14.

39. Foerstner KU, von MC, Hooper SD, Bork P: Environments shape the nucleotide composition of genomes. EMBO Rep 2005, 6(1469-221; 12):1208-1213.

40. Chen LL, Zhang CT: Seven GC-rich microbial genomes adopt similar codon usage patterns regardless of their phylogenetic lineages. Biochem Biophys Res Commun 2003, 306(0006-291; 1):310-317.

41. Novichkov PS, Omelchenko MV, Gelfand MS, Mironov AA, Wolf YI, Koonin EV: Genome-wide molecular clock and horizontal gene transfer in bacterial evolution. J Bacteriol 2004, 186(19):6575-6585.

42. Snyder EE, Kampanya N, Lu J, Nordberg EK, Karur HR, Shukla M, Soneja J, Tian Y, Xue T, Yoo H, Zhang F, Dharmanolla C, Dongre NV, Gillespie JJ, Hamelius J, Hance M, Huntington KI, Jukneliene D, Koziski J, Mackasmiel L, Mane SP, Nguyen V, Purkayastha A, Shallom J, Yu G, Guo Y, Gabbard J, Hix D, Azad AF, Baker SC, Boyle SM, Khudyakov Y, Meng XJ, Rupprecht C, Vinje J, Crasta OR, Czar MJ, Dickerman A, Eckart JD, Kenyon R, Will R, Setubal JC, Sobral BW: PATRIC: the VBI PathoSystems Resource Integration Center. Nucleic Acids Res 2007, , 35 Database: D401-6.

43. Reva ON, Tummler B: Global features of sequences of bacterial chromosomes, plasmids and phages revealed by analysis of oligonucleotide usage patterns. BMC Bioinformatics 2004, 5:90.

44. Pride DT, Meinersmann RJ, Wassenaar TM, Blaser MJ: Evolutionary implications of microbial genome tetranucleotide frequency biases. Genome Res 2003, 13(2):145-158.

45. R Development Core Team: R: A language and environment for statistical computing.[http://www.R-project.org].

46. Karlin S: Statistical significance of sequence patterns in proteins. Curr Opin Struct Biol 1995, 5(0959-440; 3):360-371.

47. Karlin S, Mrazek J, Campbell AM: Compositional biases of bacterial genomes and evolutionary implications. J Bacteriol 1997, 179(12):3899-3913.

48. van Passel MW, Kuramae EE, Luyf AC, Bart A, Boekhout T: The reach of the genome signature in prokaryotes. BMC Evol Biol 2006, 6:84.
49. Altschul SF, Gish W, Miller W, Myers EW, Lipman DJ: Basic local alignment search tool. J Mol Biol 1990, 215(3):403-410.

50. Hiller NL, Janto B, Hogg JS, Boissy R, Yu S, Powell E, Keefe R, Ehrlich NE, Shen K, Hayes J, Barbadora K, Klimke W, Dernovoy D, Tatusova T, Parkhill J, Bentley SD, Post JC, Ehrlich GD, Hu FZ: Comparative genomic analyses of seventeen Streptococcus pneumoniae strains: insights into the pneumococcal supragenome. J Bacteriol 2007, 189(22):8186-8195.

51. Tekaia F, Yeramian E: Evolution of proteomes: fundamental signatures and global trends in amino acid compositions. BMC Genomics 2006, 7:307

52. Koonin EV, Wolf Yl: Genomics of bacteria and archaea: the emerging dynamic view of the prokaryotic world. 2008, 36(21):6688-6719.

doi:10.1186/1471-2148-10-249

Cite this article as: Bohlin et al:: Genomic comparisons of Brucella spp. and closely related bacteria using base compositional and proteome based methods. BMC Evolutionary Biology 2010 10:249.

\section{Submit your next manuscript to BioMed Central and take full advantage of:}

- Convenient online submission

- Thorough peer review

- No space constraints or color figure charges

- Immediate publication on acceptance

- Inclusion in PubMed, CAS, Scopus and Google Scholar

- Research which is freely available for redistribution

Submit your manuscript at www.biomedcentral.com/submit
Ciomed Central 